\title{
Encountering emotions in the field: an X marks the spot
}

\author{
By Anne Monchamp (Macquarie University)
}

This paper will examine the role of emotions in fieldwork by discussing the dialogical nature of fieldwork as a research tool. It is argued that fieldwork is based on information gathered through relationships, and therefore the emotional elements of those associations are relevant to the ethnographic writing that is produced. Further this paper will address how acknowledging the role of emotions as a part of fieldwork and the overall ethnographic research process is important; however, simply recognizing that emotions are a part of fieldwork is possibly to underplay their potentially more catalytic role in the learning process in as much as it is often through our emotional reactions that we come to understand.

\begin{abstract}
For the lay person, such as myself, the main evidence of a problem is the simple fact that ethnographic writing tends to be surprisingly boring. How, one asks constantly, could such interesting people doing such interesting things produce such dull books? What did they have to do to themselves? (Pratt 1986:33)
\end{abstract}

\section{Introduction}

'Boring' is a word that is often used by lay people to describe academic writing of all kinds but, as Pratt (1986) points out, this is particularly remarkable in the case of anthropology, because fieldwork is generally nothing if not interesting. One has to wonder why the colourful and frequently emotionally charged experiences of fieldwork are often edited out of the final accounting. In short: why is ethnographic writing so different from ethnographic fieldwork in a discipline that is explicitly demarcated by its use of fieldwork as a research tool (Amit 2000:1)? Evidence of fieldwork is almost always included in anthropological writing, but the experiential emotional happenings that make up fieldwork are much harder to capture within ethnography - both because this sort of content is often perceived as outside the ethnographic scope, and because this sort of writing is often outside the necessary skill base of the anthropologist. I will touch on issues related to both of these points, but I will focus primarily on the former in light of the emotional aspects of fieldwork as a disciplinary pursuit.

One unique feature of fieldwork as a research methodology is that it takes place 'in the world' as opposed to a lab or office, while most other forms of research are done under controlled circumstances. In these structured environments, the investigator returns home to his or her 'real life' after a day's research, whereas for fieldworkers life and lab intersect. The fact that there are often no dividing lines separating personal and professional during fieldwork has far-reaching implications, particularly in relation to the emotional involvement of the researcher in the research process. Beyond these partitioning concerns, the diverse individual make-up of a community, 
in combination with the fact that fieldwork, rather than being a specific form of research, is a term that signifies many ways of being and doing, means that each field experience will be unique.

This paper will address questions about the relationship between emotions and fieldwork by looking at several aspects of the fieldwork process in light of my own fieldwork in the Australian Central Desert community of Alpurrurlam. My research is directed at studying autobiographical memory in a cultural context. I did this by collecting life stories from many of the older women in Alpurrurlam. Having autobiographical memory as a topic means that I often discuss people's pasts, and some memories may be both personal and emotional for the rememberer, so many of the situations I found myself in were not just emotional for me but also for others involved in the research encounter. For the sake of confining myself to a concise topic here, however, the scope of this paper is primarily limited to the role of the fieldworker's emotions.

\section{Crossing lines}

Before leaving for my fieldsite, I was advised by several people to keep my personal journal and my field journal separate. There were several reasons for this counsel; paramount among them was that my fieldnotes could be subpoenaed if a land claim were filed for this area, and it is possible that some of my personal experiences and opinions should remain just that. Initially this separation was a simple matter as my field journal consisted of sparse entries like 'walked around town today-no one spoke to me'. By contrast, my personal journals were filled with long rambling entries of endless self-doubt as to whether this whole fieldwork idea was even remotely a reasonable undertaking. Clearly there was little overlap.

However, as months passed, the line between personal and professional blurred. I didn't just work in the community, I lived there, and through living there I had made friends. My conversations with those friends were often both personal and professional, because my friends were also the subject of my research. This distinction between personal and professional can create conflict and confusion when, for example, a fieldworker shares personal information about herself with members of the community who are both friends and research subjects. One problem involved here is that while other people's personal lives are often a part of the research, the researcher's personal life is not. However, while the investigator's personal life is not usually a part of the research, it is often only through the sharing of personal information that an anthropologist is given access to the lives of others.

I found myself in just such a situation one day while fishing with some ladies from town. Every trip to the river is an adventure and for me usually a lot of work. I get ordered around, both because I work with older women and they are my elders, and also because they know they have something I want and rightly feel I should give something in return. I am told to get wood for a fire. I am told to dig a pit. I wrap the kangaroo tails in aluminum foil, put them in the pit and cover them with coals. After the exertion in the heat it is pleasant to sit by a roasting fire-well, not pleasant, but it keeps the flies away. As we wait for the tails to cook one of the old ladies asks me if I have a man in my life. I feel my heart seize in my chest and my already flushed face gets hot and red like the embers of the fire. I say 'no', but I don't look at her, I just look at the river. I don't really want her to see my eyes welling up with tears. She asks 
me why I don't have a man and I briefly wonder if she is channeling my grandmother, but rather than ask I tell her that I had a man but that he went and found himself another woman and left me. It was only a month ago that he walked out on me with that phone call- 'There is no easy way to say this but I met someone else, her name is Samantha,' like I care what her name is, I still feel the indignation. I try to hold back the tears, I wonder if it is professional to cry? Do I need to be professional? All the questions that I bring with me to the field and those I find here rush through me, like the blood rushing through my ears, and I wonder again if I am ready for fieldwork. 'Rubbish man that one. I know that, lotta rubbish man,' she tells me and then she and the other women around the fire tell me about the men in their lives who were 'rubbish men'. We shared all afternoon and they helped me understand their feelings toward relationships and men. I learned that cheating is regarded with equal hostility among these women, but that two of the women present were, before his death, married to the same man, and this was not regarded negatively at all. By the end of the day I felt a lot less like crying. I loved each and every one of them from that day forward. Not just because they helped me with my research, but because they helped me with my broken heart.

However, this event, while being important to our personal relationship as friends, also impacted the way my research progressed, as the discussion about my personal life did not end on that day. My status, and my feelings about said status, were often a topic of conversation. For example, one day while talking about an upcoming football match in town, one lady said to me: 'Lotta Akamarra men be comin' (Akamarra is one of the four kinship groups in the Alyawarr system). I asked how she knew that Akamarra men would be coming to the games and she responded: 'Must be... you need to find a man.' It was with this seemingly passing comment that I became aware that I had been incorporated into the kinship system. As a researcher I was elated at this revelation; as a single woman, I was a little intimidated.

After this I began to be introduced to people based on their relationship to me. I was told 'this here is your sister', and perhaps most poignantly, 'that one there is your baby'. Being a woman I did not feel the need to defend myself against this last introduction, but it did bring home to me the point that I now stood in some relation to virtually all members of my community and that this relatedness placed certain obligations on me and afforded me some rights to call on obligations. As Shweder points out, 'sometimes dormant or unknown emotional and cognitive structures within oneself are activated through participation. When they are activated, all of a sudden understanding occurs in a far more profound way' (1997:162); and for me they made possible a much more profound understanding of the kinship system.

In settings such as a psychological interview or a sociological survey, a one-way sharing of information is common, and distinct lines between personal and professional are often strictly enforced. In a fieldwork setting, however, this sort of separation is much less likely to be effective. If I had not shared personal information about myself with these women, it is quite likely that they would not have shared personal information with me about their lives either, and therefore, without this sort of relationship development my research would not progress. This sort of sharing is in some ways required during fieldwork; personal relationships must be formed, therefore it is important to examine how this sort of sharing impacts the picture of the community that the researcher develops. 
Since fieldworkers' emotional relationships both shape the data that they are likely to get and influence from whom they are likely to get that data, these emotional connections are integral to the fieldwork process. Hammersley points out that 'the data ethnographers use is a product of their participation in the field rather than a mere reflection of the phenomenon studied' (1992:2), hence I, like so many others, am not just studying what is here but finding what I seek. I seek stories of the past and so I find them. As Abrahams says, 'simply by asking questions (any questions)... we have already committed an unconsidered ethnocentric act' (1976:3); beyond this we are also expressing a desire, and those who fulfill our desire and answer our questions become our informants and often our friends. One reason why writing about one's subjective stance is often difficult is that in research terms the observer is not also the observed; however, in anthropology, which involves a greater degree of dialogical participation, the researcher's personal involvement-including emotional responses - are implicated to a greater degree, because the separation between personal and professional is less clear than in other research forms.

Examples of this sort of influence are prevalent in many ethnographies-sometimes explicitly but most times implicitly. An ethnographic account where the author is openly reflexive about her participation in how the story she presents unfolds is Nisa (Shostak 1981). In the epilogue of this book, Shostak tells us that when she returned to her fieldsite years after her original expedition, she was remembered by the local women as a person who always wanted to talk about sex. Earlier in the book she says of Nisa that 'one woman-Nisa-impressed me more than the others with her ability to describe her experiences' (ibid:7), and later that Nisa 'concentrated on my questions and answered them' (ibid:30). So while sex is a feature of any society that survives, the prominence of sex and gender in this book are not necessarily just a feature of !Kung society, but rather a product of a specific relationship between Nisa and Shostak, a combination of their interests that produced a specific perspective and a focus on certain issues. Shostak approached this work during a time of sexual revolution in her own culture to find other ways of dealing with gender. Nisa, rather than being a cultural model, is given a particular voice, a personal subjectivity, and while both women are in some way representatives of their respective cultures, they are also real individual people; both have a voice in the text, and both are living real lives of experience in a commensurate time if not commiserate circumstances.

I find myself in a similar position to Shostak, in that my gender became a part of the research that I was doing, for me not because I always wanted to talk about sex, but because my friends saw me as a woman with a broken heart that they wanted to fix. In my own work I will need to expose my subjective position and the influence that I, as a person, had on the construction of the data that I collected; however, perhaps for someone like myself-immersed in a research environment-being analytical rather than emotional is a way to write myself into the text. However, as all anthropology $\mathrm{PhD}$ students know, the simple phrase 'writing myself into the text' is an innocence that covers a multitude of sins. While I do plan to write my emotional stance into the text to the degree that I am able as a writer and a person, I am rather sure that Samantha will be written out of the story.

\section{Individual encounters}

Fieldwork is a vague, encompassing term, and nervous graduate students like me preparing to undertake such research frequently look to any quarter for advice on what 
to do. Given the ambiguity of fieldwork, what is sought is some solidity in the form of an activity checklist; does one do interviews, surveys or questionnaires? So often these question are met with ambiguous responses such as 'do what they do', 'don't be shy', 'talk to people' - and this advice, while sage, often leaves the solicitor feeling more confused than satisfied. The tension arises from the fact that while all anthropologists engage in fieldwork,

\begin{abstract}
they do not necessarily see this as being for method. They harbor the suspicion that methodological pursuits get in the way of participating in the flow of life of a community. They think that if you are really serious and want to get to know a place well the most important thing to do is muck around a lot. (Shweder 1997:153)
\end{abstract}

Fieldwork is often not so much a method but an anti-method; it must evolve, it must exist in its own context, and thus is always a unique combination of the fieldworker and the field. Supervisors and authors of methodological texts can offer no recipe for success and no sure-fire method for conducting an investigation, because fieldwork, like life, has no single recipe.

Beyond this inability to establish a single method, it must also be acknowledged that while anthropological fieldwork is directed at the study of culture, in order to accomplish this, one must work with individuals - individuals with a full range of personalities and dispositions. As Krupat points out, "whatever "cultures" or "peoples" do or don't do, particular persons... react to the new and other with all the range of human responses possible' (1992:15). Dealing with individuals one must take into account the unique dispositions and personalities involved, and remember that 'so-called natives can be insightful, sociologically correct, axe-grinding, selfinterested, or mistaken' (Rosaldo 1993:50) — and, I would add, they, like everyone, can also be humorous, teasing and satirical. Due, in part, to the individual combination of fieldworker and fieldsite, each fieldwork encounter will be unique.

I often found during my fieldwork that I was in the position of being a cultural child who must learn all the norms that are taken for granted by most adult members of the community. This put me in the awkward position of already being an adult while not being culturally competent, and I thus found that I was likely to get into awkward, embarrassing or even frustrating situations on a regular basis, making fieldwork an extremely emotionally charged experience. (While not all fieldworkers will share my experiences in this regard, even if emotions are not elevated by cultural transition, 'normal' emotions will occur and have value in the research process.) One reason is that communicative encounters that involve a fieldworker are of a distinctive nature, because in contrast to most discourse, which has been defined as talk that is 'mediated by a set of common background expectancies' (Rapport and Overing 2000:118), encounters with a fieldworker from a different culture occur where the background expectancies are explicitly not shared.

In writing ethnography, it is important to allow the individuals who comprise the cultural group being studied their emotional position in the world, but also to express the emotional position of the fieldworker, which will allow the reader, who may not share background expectancies with either party, a context in which to know 'who is speaking to whom, about what, for what purposes, and under what circumstances?' (Rosaldo 1993:54). Based on my own experience, it is often our emotions that signal when certain background expectancies are not shared. An example of this from my own fieldwork happed while I was fairly new in town. 
I was walking along the road and encountered a woman I had met several times. She stopped to say hello and I noticed that her hair had been cut short. I, being the sensitive person that I am, commented to her that I liked her hair cut; she looked at me oddly and walked away without comment. I felt uncomfortable and embarrassed, but unsure about what it was that I had done wrong. As I continued on my way to the shop I noticed, perhaps in part because of my recent encounter, that several women had recently cut their hair. Later that day, after much inquiry on my part, I learned that all the ladies in town that had cut their hair had done so in 'sorry camp' for a relative that had died. These women had cut their hair as a physical manifestation of their loss, and my comment was 'hey, don't you look nice'. Needless to say I felt very foolish for telling this woman that her grief looked good.

In this story my sense of humiliation arose because I unintentionally came into conflict with social norms. My emotional response was a signal that I had encountered a point of divergence between my culture, and my expectations of this culture, and the reality I found. The emotional response was like an ' $X$ ' that marked the spot of where to begin investigations related to why this difference occurred. Without our emotional responses we could traverse any number of cultural boundaries without ever marking their existence. Acknowledging the role of emotions as a part of fieldwork and the overall ethnographic research process - a role that may be atypical to other forms of research-is important; however, just recognizing that emotions are a part of fieldwork is possibly to underplay their potentially more catalytic role in the learning process. In some situations it is precisely the personal emotional response of the fieldworker that can bring home the meaning of culturally framed events, because 'emotions are not simply reactions to what happens, but interpretations of an event, judgments' (Myers 1991:106).

\section{Conclusion}

Writing about one's subjective stance is often difficult because it is not explicitly relevant if the observer is constituted as being divorced from the observed. However, in fieldwork, which involves a more dialogical form of participation, the researcher's subjectivity is implicated in the selection of information through field participation, along with other aspects of the overarching learning process of which fieldwork is a part, and is therefore relevant not only to the research but also to the writing that is produced. The emotional circumstances and relationships that fieldworkers encounter during research are not often included in the final product, both because this sort of content is often perceived as outside the ethnographic scope, and also because this sort of writing is often outside the capabilities of the anthropologist as author.

Pratt points out how the omission of emotion places ethnography alongside other 'boring' forms of academic writing, whilst the experience of fieldwork is often anything but. Including experiential information about the researcher and his or her emotional positions in the research process will not only enlighten readers of ethnography about anthropological encounters and their resulting epistemological claims, but may also serve to increase the readership of ethnography because people find people interesting. I for one may not have the literary grace to express my emotional stance in a way that is commensurate to experience, but I do attempt to convey the emotional context of my learning encounters. 
Some anthropologists have expressed feelings of intimidation at exposing their emotions for public review along with their more narrowly defined academic results, but, for me, given the fact that I had, particularly in the initial stages of my fieldwork, feelings of being intimidated and exposed, it is perhaps appropriate that I should have analogous feelings about my writing so that my readers will know not only what I think I learned but how it is that I believe I learned it. I contend that emotions are important in ethnographic writing because they are implicated in the production of knowledge, and further that while anthropology may be defined by fieldwork, fieldwork itself is, because of its dialogical nature, a unique combination of fieldworker and fieldsite.

\section{References}

Abrahams, Roger D.1976. Talking Black. Rowley, MA: Newbury.

Amit, Vered. 2000. Introduction. In Constructing the Field: Ethnographic Fieldwork in the Contemporary World (ed.) Vered Amit, 1-18. London: Routledge.

Hammersley, Martyn. 1992. What's Wrong With Ethnography? Methodological Explorations. London: Routledge.

Krupat, Arnold. 1992. Ethnocriticism: Ethnography, History, Literature. Berkeley and Oxford: University of California Press.

Myers, Fred R. 1991 [1986]. Pintupi Country, Pintupi Self. Los Angeles and London: University of California Press.

Pratt, Mary Louise. 1986. Fieldwork in common places. In Writing Culture: The Poetics and Politics of Ethnography (eds.) James Clifford and George Marcus, 27-50. Berkeley and London: University of California Press.

Rapport, Nigel and Joanna Overing. 2000. Social and Cultural Anthropology: The Key Concepts. London and New York: Routledge.

Rosaldo, Renato. 1993. Culture and Truth: The Remaking of Social Analysis. Boston: Beacon Press.

Shostak, Marjorie. 1981. Nisa: The Life and Words of a !Kung Woman. Cambridge, Mass: Harvard University Press.

Shweder, Richard A. 1997. The surprise of ethnography. Ethos 25(2), 152-163.

\section{About the author}

Anne Monchamp is currently working on her $\mathrm{PhD}$ in Anthropology at Macquarie University in Sydney, Australia. Her thesis is designed around the anthropological, psychological and philosophical theme of autobiographical memory. Her fieldwork was carried out in the Australian Central Desert community of Alpurrurlam. Her interests include memory, mind, dreams and travel/tourism. Anne can be contacted at anne.monchamp@scmp.mq.edu.au 